\title{
COMENTARIO A LA STC 1/2018, DE 11 DE ENERO (PLENO), SOBRE LA INCONSTITUCIONALIDAD DEL ART. 73.E) DE LA LEY DEL CONTRATO DE SEGURO
}

\author{
Guillermo SCHUMANN BARRAGÁN \\ Contratado Predoctoral FPU \\ Departamento de Derecho Procesal y Derecho Penal \\ Facultad de Derecho. Universidad Complutense de Madrid \\ gschuman@ucm.es
}

\section{INTRODUCCIÓN}

El 7 de febrero del 2018 se publicó en el BOE la Sentencia de Pleno del Tribunal Constitucional núm. 1/2018, de 11 de enero, por la que, al resolver una cuestión de inconstitucionalidad elevada por la Sala de lo Civil y Penal del Tribunal Superior de Justicia de Cataluña, declaró inconstitucional y nulo el art. 76.e) de la Ley 50/1980, de 8 de octubre, de Contrato de Seguro (en adelante, LCS), por ser contrario a los arts. 24 y 117.3 de la Constitución Española.

$\mathrm{El}$ art. 76.e) LCS reconocía al asegurado «el derecho a someter a arbitraje cualquier diferencia que pueda surgir entre él y el asegurador sobre el contrato de seguro». La norma se integraba en la sección novena del título II relativa al «seguro de defensa jurídica». Esta sección fue introducida por la Ley 21/1990, de 19 de diciembre, que transpuso al ordenamiento jurídico español la Directiva 88/357/CEE y, especialmente, la Directiva 87/344/CEE sobre coordinación de las disposiciones legales, reglamentarias y administrativas relativas al seguro de defensa jurídica. El art. 76.e) LCS, en concreto, se ocupaba de transponer el art. 6 de la referida Directiva $87 / 344 / \mathrm{CEE}^{1}$, cuya previsión se mantiene en la actualidad en el art. 203

${ }^{1}$ Art. 6 de la Directiva 87/344/CEE sobre coordinación de las disposiciones legales, reglamentarias y administrativas relativas al seguro de defensa jurídica: «Los Estados miembros adoptarán todas las disposiciones útiles a fin de que, sin perjuicio de cualquier dere- 
de la Directiva 2009/138/CEE sobre el seguro de vida, el acceso a la actividad de seguro y de reaseguro y su ejercicio ${ }^{2}$.

La sentencia, de la que fue ponente la magistrada Encarnación Roca Trías, cuenta con tres votos particulares formulados por los magistrados Fernando Valdés Dal-Ré, Juan Antonio Xiol Ríos y Antonio Narváez Rodríguez (al que se adhirió Ricardo Enríquez Sancho).

\section{ANTECEDENTES DE HECHO}

La cuestión de inconstitucionalidad se planteó en el marco de un procedimiento de nombramiento judicial de árbitro instado ante la Sala de lo Civil y Penal del Tribunal de Justicia de Cataluña por un asegurado que alegaba la negativa de la entidad aseguradora a someter la disputa surgida entre ambos a arbitraje conforme al art. 76.e) LCS y solicitaba el nombramiento de árbitro «por imperativo legal» ${ }^{3}$.

Según el TSJ de Cataluña, el art. 76.e) LCS podía ser contrario a los arts. 24.1 y 117.3 de la Constitución por establecer una suerte de arbitraje obligatorio para una de las partes del contrato: la entidad aseguradora. De la lectura e interpretación del precepto, el órgano jurisdiccional constató que la norma concedía al asegurado la posibilidad de imponer el arbitraje a la aseguradora por su sola y exclusiva voluntad. A su juicio, el hecho de que el precepto fuera fruto de la transposición de las Directivas 87/344/ CEE y 88/357/CEE, puesto en relación con el principio de primacía del Derecho comunitario, no era un argumento válido para sustentar la adecuación de la norma a la CE, ya que las citadas normas comunitarias tenían

cho de recurso a una instancia jurisdiccional que eventualmente hubiera previsto el Derecho nacional, se prevea un procedimiento arbitral u otro procedimiento que ofrezca garantías comparables de objetividad que permita decidir, en caso de divergencia de opiniones entre el asegurador de la defensa jurídica y su asegurado, respecto a la actitud que deba adoptarse para la solución del desacuerdo. El contrato de seguro deberá mencionar el derecho del asegurador a recurrir a tal procedimiento».

2 Art. 203 de la Directiva 2009/138/CEE sobre el seguro de vida, el acceso a la actividad de seguro y de reaseguro y su ejercicio: «Los Estados miembros preverán, con vistas a la solución de todo litigio que pueda surgir entre la empresa de seguros de defensa jurídica y el asegurado y sin perjuicio de cualquier derecho de recurso a una instancia jurisdiccional que eventualmente hubiera previsto el Derecho nacional, un procedimiento arbitral u otro procedimiento que ofrezca garantías comparables de objetividad. El contrato de seguro deberá prever el derecho del asegurado a recurrir a tales procedimientos».

${ }^{3}$ La facultad de solicitar el nombramiento judicial de árbitros es una posibilidad contemplada en los arts. 8 y 15.3 de la Ley de Arbitraje. 
como finalidad «fomentar» el arbitraje y no contemplaban la necesidad de imponerlo unilateralmente. Tanto el art. 6 de la Directiva 87/334/CEE como el art. 203 de la Directiva 2009/138/CEE, entendidos en su recto sentido según la Sala, disponían que el procedimiento arbitral se establecería sin perjuicio de cualquier derecho de recurso a una instancia jurisdiccional; instancia que no puede referirse en modo alguno a la demanda de anulación, por cuanto esta se circunscribe a un juicio externo de legalidad del laudo arbitral. De esta manera, se consideró que, en caso de que el asegurado hiciera uso del derecho que le concedía el precepto cuestionado, se generaba una exclusión ex lege del derecho a la tutela judicial efectiva de la aseguradora (art. $24 \mathrm{CE}$ ), prescindiendo de su autonomía de la voluntad -que, en última instancia, se constituye como la esencia y fundamento de la institución arbitral-. Asimismo, se consideraba que si el art. 76.e) LCS efectivamente permitía en el marco de una relación jurídica bilateral imponer el arbitraje unilateralmente, se estaría atribuyendo ope legis las potestades jurisdiccionales a un árbitro, vulnerando el principio de exclusividad de la jurisdicción (art. 117.3 CE) ${ }^{4}$.

Tras la presentación de observaciones por parte de la Fiscalía General del Estado, el Pleno del Tribunal Constitucional acordó admitir a trámite la cuestión planteada, reservó para sí su conocimiento y publicó su incoación en el BOE. En el seno del procedimiento formularon alegaciones la Abogacía del Estado, el Ministerio Fiscal y la representación procesal del asegurado.

La Abogacía del Estado interesó la desestimación de la cuestión recordando que el precepto cuestionado transponía una directiva comunitaria. Así, al ser el derecho a la tutela judicial efectiva un derecho de configuración legal, el legislador comunitario podía incidir en él en aquellas materias cuya competencia tuviera atribuida (art. $93 \mathrm{CE}$ ). De esta manera, el legislador europeo configuraba, mediante las directivas transpuestas en el art. 73.e) LCS, el ejercicio del derecho en una materia de su competencia; configu-

${ }^{4}$ Para apoyar sus conclusiones y las dudas sobre la inconstitucionalidad del precepto cuestionado, el TSJ de Cataluña hace referencia en su auto de planteamiento al Real Decreto Legislativo 6/2004, de 29 de octubre, por el que se aprueba el Texto Refundido de la Ley de Ordenación y Supervisión de Seguros Privados. Según su art. 61: «1. Los conflictos que puedan surgir entre tomadores de seguro, asegurados, beneficiarios, terceros perjudicados o derechohabientes de cualesquiera de ellos con entidades aseguradoras se resolverán por los jueces y tribunales competentes. 2. Asimismo, podrán someter voluntariamente sus divergencias a decisión arbitral en los términos del art. 31 de la Ley 26/1984, de 19 de julio, General para la Defensa de los Consumidores y Usuarios, y sus normas de desarrollo» (la cursiva es nuestra). 
ración que, además, no afectaba a su contenido esencial (art. 53 CE). Asimismo, se sostenía que el arbitraje es una institución adecuada a los valores constitucionales, por lo que se estimaba conforme a la norma fundamental que, en determinados casos en los que el legislador lo estimara pertinente, se otorgara a la parte contractual débil la posibilidad de imponer el arbitraje como forma de solución del conflicto surgido. En definitiva, la Abogacía del Estado entendía que el art. 73.e) LCS transponía correctamente las directivas comunitarias y, por tanto, debía entenderse conforme a la Constitución en aplicación del principio de primacía del Derecho europeo.

La Fiscalía General del Estado interesó la estimación de la cuestión. En resumen, recordaba que el derecho a la tutela judicial efectiva, como cualquier otro derecho fundamental, está sometido a limitaciones. Estas deben estar encaminadas a conseguir fines constitucionalmente válidos y no pueden suponer trabas procesales arbitrarias o caprichosas al ejercicio del Derecho. Tras señalar que la posibilidad de contemplar el arbitraje por vía legal es perfectamente posible cuando atiende a finalidades positivas - por ejemplo, el reequilibrio de las partes en contratos de adhesión-, se recuerda que esta posibilidad exige como requisito sine qua non la voluntad concurrente de los contratantes. Como consecuencia de lo anterior se concluye que la posibilidad de que el asegurado pueda obligar a la aseguradora a acudir a la vía arbitral choca con un obstáculo infranqueable: el derecho a la tutela judicial efectiva puesto en relación con la autonomía de la voluntad.

Por último, la representación procesal del asegurado presentó alegaciones por las que manifestó que el art. 76.e) LCS era el producto de la transposición de una directiva comunitaria cuya finalidad era la protección de la parte más débil del contrato y que, por tanto, la controversia entre las normas nacionales y comunitarias debía resolverse a favor de estas últimas en base al principio de primacía del Derecho de la Unión.

\section{FUNDAMENTACIÓN JURÍDICA DE LA STC 1/2018}

En primer lugar, el Tribunal Constitucional se encarga de delimitar de forma clara cuál es el objeto de su enjuiciamiento: única y exclusivamente el art. 76.e) LCS, «dejando aparte cualquier cuestión relacionada con el enjuiciamiento del Derecho de la Unión». De esta manera, se advierte desde un primer momento la intención de no entrar a analizar, tal como planteaba la Abogacía del Estado y la representación procesal del asegurado, la adecuación de normas comunitarias de Derecho derivado - las 
Directivas 88/357/CEE, 87/344/CEE y 2009/138/CEE- con la Constitución. Asimismo, se niega que el papel del Tribunal deba ser enjuiciar la aplicación del Derecho de la Unión y la adecuada transposición de las directivas por parte del legislador nacional. El objeto de la cuestión que se somete a análisis es la adecuación de una norma nacional concreta -el art. 76.e) LCS - con la Constitución española y no la adecuación del Derecho de la Unión con la Constitución ni la adecuación de la norma nacional con el Derecho de la Unión 5 .

Dicho esto, el Alto Tribunal recuerda que el derecho a la tutela judicial efectiva consagrado constitucionalmente en el art. 24 CE es un derecho prestacional de configuración legal que se refiere a una potestad del Estado atribuida al poder judicial. Así las cosas, el derecho a la tutela judicial efectiva está supeditado a la concurrencia de los requisitos legalmente establecidos por el legislador, los cuales serán constitucionalmente admisibles siempre que no supongan un obstáculo arbitrario o caprichoso al ejercicio del Derecho.

Dando un paso adelante en la cuestión, el Tribunal recuerda el anclaje constitucional de la institución arbitral en nuestro ordenamiento jurídico y su concepción como un «equivalente jurisdiccional». La exclusividad jurisdiccional consagrada en el art. 117.3 CE no afecta a la validez constitucional del arbitraje, por cuanto, si bien es verdad que el derecho a la tutela judicial efectiva tiene carácter irrenunciable e indisponible, «ello no impide que pueda reputarse constitucionalmente legítima la voluntaria y transitoria renuncia al ejercicio de las acciones» (FJ 3). Una renuncia que, como tal, debe ser explícita, clara, terminante e inequívoca. De esta manera, se concluye categóricamente que la base y sustento del arbitraje se encuentra en la autonomía de la voluntad de las partes como una manifestación y proyección concreta de la libertad como valor superior del ordenamiento jurídico (art. 1.1 CE).

Lo anterior es la razón por la que el Tribunal ha considerado en anteriores ocasiones contrario al derecho a la tutela judicial efectiva la imposi-

5 Debe señalarse que, pese a que el Tribunal diga expresamente que no le corresponde analizar la correcta transposición de la directivas comunitarias, en el fundamento jurídico 5 afirma expresamente que tanto el art. 203 de la Directiva 2009/138/CEE como su precedente art. 6 de la Directiva 87/344/CEE no imponen que el procedimiento arbitral «excluya el acceso a la jurisdicción ordinaria». Por tanto, al no precisarse en la norma comunitaria cómo debe configurarse el procedimiento arbitral en este tipo de contratos de seguro, el Tribunal entiende que el legislador nacional «no ha apurado el margen de apreciación» que le otorgaban las directivas a fin de cumplir con sus obligaciones de transposición y con las exigencias constitucionales derivadas del art. $24 \mathrm{CE}$ en relación con el arbitraje. 
ción de un arbitraje obligatorio (STC 174/1995). La falta de voluntad de ambas partes hace que no concurra el elemento legitimador de la institución arbitral. De esta manera, solo una renuncia al ejercicio del derecho a la tutela judicial efectiva basada en la autonomía de la voluntad — rectus, la renuncia a un ejercicio «puntual» del derecho fundamental— satisface los principios constitucionales en los que se apoya el arbitraje.

$\mathrm{Y}$ esto es así ya que, como es evidente, una vez sometida la disputa a arbitraje queda vedado el acceso a la jurisdicción ordinaria. El recurso por nulidad del laudo arbitral se circunscribe a un juicio externo sobre garantías formales y de legalidad del laudo arbitral, por lo que se impide cualquier replanteamiento sobre el fondo del litigio debatido en el proceso arbitral. A los meros efectos dialécticos, el Tribunal plantea que solo sería compatible el arbitraje obligatorio con el derecho a la tutela judicial efectiva si no se excluyera el ulterior conocimiento jurisdiccional de la cuestión en cuanto al fondo.

Así, y a modo de primera conclusión, el arbitraje será un mecanismo constitucionalmente válido siempre y cuando sea «fruto del concurso de voluntades de ambas partes del litigio, las cuales voluntariamente desplazan el juego del art. $24 \mathrm{CE}$ o, lo que es lo mismo, renuncian expresa y puntualmente al ejercicio del derecho a la tutela de los jueces y magistrados» (FJ 4).

Dicho esto, y expuesta la jurisprudencia constitucional existente sobre el derecho a la tutela judicial efectiva y la institución arbitral, el Tribunal procede a analizar si el contenido del art. 76.e) LCS es contrario a la Constitución. A este respecto, el órgano constitucional añade que la posible vulneración vendría dada no tanto por la posibilidad unilateral inicial del asegurado de someter la disputa a arbitraje, sino por impedir su posterior acceso a la jurisdicción.

Entrando al meollo de la cuestión, y dando por hecho que el art. 76.e) LCS supone una limitación real al derecho a la tutela judicial efectiva de la entidad aseguradora en tanto en cuanto le impone someterse a un procedimiento arbitral sin su consentimiento, el Tribunal analiza si esta limitación es constitucionalmente admisible. En primer lugar, se afirma que el precepto cuestionado no puede considerarse como un obstáculo arbitrario o caprichoso para ejercitar el derecho a la tutela judicial efectiva, sino que, por el contrario, persigue la finalidad de fomentar el arbitraje como medio idóneo para la solución de conflictos mientras se otorga una especial protección al asegurado — como parte débil de la relación contractual—. Sin embargo, el Tribunal entiende que estos fines constitucionalmente legíti- 
mos no justifican la restricción al derecho a la tutela judicial efectiva de la aseguradora que supone el arbitraje obligatorio.

De esta manera, el Tribunal entiende que la «imposición de un arbitraje como el previsto en el art. 76.e) LCS vulnera el derecho a la tutela judicial efectiva garantizado en el art. $24 \mathrm{CE}$, pues impide el acceso a la jurisdicción de los juzgados y tribunales de justicia, que, ante la falta de la voluntad concurrente de los litigantes, son los únicos que tienen encomendada constitucionalmente la función de juzgar y hacer ejecutar lo juzgado (art. $117 \mathrm{CE}) \gg(\mathrm{FJ} \mathrm{4})$.

\section{VOTOS PARTICULARES}

El primer voto particular es el formulado por Fernando Valdés Dal-Ré ${ }^{6}$ sosteniendo que el fallo de la cuestión debió ser desestimatorio. El magistrado recuerda, tal como puntualiza la sentencia, que el arbitraje obligatorio no vulnera per se el derecho a la tutela judicial efectiva. El mecanismo será contrario a la Constitución en tanto en cuanto se limiten las oportunidades de los órganos jurisdiccionales de revisar la decisión arbitral. A sensu contrario, un arbitraje obligatorio sería compatible con la Constitución si existen mecanismos procesales que permitan un control judicial sobre el fondo del laudo. Por esta razón, el magistrado entiende que al art. 73.e) LCS «no se le puede tachar de lesionar de manera directa ninguno de los preceptos constitucionales». El reproche principal a la mayoría se dirige en no haber puesto en relación el precepto controvertido con la legislación arbitral y con las normas procesales concretas que impiden la revisión sobre el fondo del asunto, pues solo así podría calificarse de inconstitucional el art. 73.e) LCS. Por último, se realiza una comparación y se pone en evidencia la (aparente) contradicción existente entre la sentencia comentada y las SSTC 119/2014 y 8/2015, que declararon la constitucionalidad del arbitraje laboral obligatorio, ya que ambas tienen como finalidad la protección de la parte débil del contrato.

El segundo voto particular es el formulado por Juan Antonio Xiol Ríos. El magistrado inicia su exposición explicando que el desacuerdo con la mayoría tiene como base la incorrecta concepción de la naturaleza de la

${ }^{6}$ Para el magistrado, de entrada, la cuestión debió haber sido inadmitida por inadecuada formulación del juicio de relevancia. Por esta razón se realiza una adhesión en este punto al voto particular formulado por Antonio Narváez Rodríguez que se expondrá más adelante. 
institución arbitral. Para él, el problema se sitúa en entender el arbitraje como un «equivalente jurisdiccional»o «sucedáneo» de la función jurisdiccional, lo cual empaña o contamina el entendimiento de los principios constitucionales que son aplicables para resolver la cuestión. La forma correcta de entender el arbitraje es concebirlo como una institución de contenido propio, de naturaleza contractual, que tiene su anclaje constitucional en el art. $10 \mathrm{CE}-\mathrm{y}$ no en el art. $24 \mathrm{CE}-$. Por otro lado, el magistrado entiende que la cuestión tendría que haber sido inadmitida de plano por no superar el juicio de relevancia (es decir, el criterio judicial acerca de la aplicabilidad de la norma al caso concreto). A este respecto se pone de manifiesto que en el litigio principal existía en la póliza contractual una cláusula que reconocía el derecho del asegurador a someter la discrepancia al procedimiento arbitral. Según se puede desprender de las alegaciones de las partes, para el demandante ya existía un convenio arbitral desde el momento mismo en que se suscribió el contrato de seguro. De esta manera, el quid de la cuestión se encontraría no tanto en el art. 76.e) LCS, que reconoce en abstracto el derecho subjetivo del asegurado, sino en el art. 76.f $)^{7}$, que impone a la aseguradora la obligación de insertar en sus pólizas el reconocimiento del derecho y en la consideración de esta estipulación como un auténtico convenio arbitral. Regresando al fondo de la cuestión, el magistrado entiende (como concluyó la sentencia) que la falta de consentimiento de ambas partes plasmada en el convenio arbitral limita el derecho a la tutela judicial efectiva de la entidad aseguradora, pero, a diferencia de la mayoría, considera que esta limitación se encuentra justificada en la protección de los consumidores como parte débil del contrato y bien jurídico protegido constitucionalmente (art. $51 \mathrm{CE})^{8}$. Por último, se expresa la contradicción de afirmar, tal como lo hace la sentencia, que el precepto no sería inconstitucional si se permitiera la revisión sobre el fondo del laudo, ya que esto, además de privar de cualquier eficacia prác-

7 El art. 76.f) LCS dispone: «La póliza del contrato de seguro de defensa jurídica habrá de recoger expresamente los derechos reconocidos al asegurado por los dos artículos anteriores. En caso de conflicto de intereses o de desavenencia sobre el modo de tratar una cuestión litigiosa, el asegurador deberá informar inmediatamente al asegurado de la facultad que le compete de ejercitar los derechos a que se refieren los dos artículos anteriores».

${ }^{8}$ Según el voto particular, el objeto del contrato de seguro que nos ocupa es, precisamente, la defensa y asistencia letrada en un procedimiento judicial. Por tanto, el magistrado entiende que el obligar al consumidor a acudir a un procedimiento en el cual necesitará, justamente, la prestación que solicita de la entidad aseguradora sería, cuando menos, paradójico. De esta manera, llega a la conclusión de que el derecho de someter unilateralmente la controversia a arbitraje es un medio idóneo para la protección de los consumidores y usuarios al encontrarnos ante un mecanismo rápido, sencillo y económico. 
tica al arbitraje, haría inconstitucional todo el procedimiento arbitral previsto legalmente?.

El último voto particular es el formulado por Antonio Narváez Rodríguez (al que también se adhiere Ricardo Enríquez Sancho). En primer lugar, y en sintonía con el resto de votos particulares, el magistrado sostiene que la cuestión tendría que haber sido inadmitida por no haberse formulado correctamente el juicio de relevancia. Según parece desprenderse del auto de planteamiento de la cuestión prejudicial del TSJ de Cataluña y de las actuaciones remitidas al Tribunal, la demanda de nombramiento de árbitro tenía como fundamento la póliza de seguro suscrita y el art. 73.e) LCS. Por tanto, se mostraba imprescindible para el juicio de relevancia de la cuestión realizar un análisis de la póliza de seguro para comprobar si en la misma existía verdaderamente un convenio arbitral. Esto tendría una incidencia directa en el juicio de relevancia, ya que si la póliza incluía un convenio arbitral, el precepto relevante para resolver la cuestión era el art. 73.f) LCS, que impone la obligación de la aseguradora de incorporarlo en la póliza, o si, por el contrario, no se hacía ninguna referencia en la póliza y, por tanto, se podía considerar que el asegurado estaba ejercitando directamente el derecho legalmente reconocido en el art. 73.e) LCS. Al ser la propia Ley de Arbitraje la que contempla en su art. 9 la posibilidad de que el convenio arbitral adopte «la fórmula de una cláusula incorporada en el contrato», se muestra imprescindible analizar la póliza para concluir si existe un verdadero convenio arbitral entre las partes ${ }^{10}$. Respecto al fondo del asunto, se acepta que, al no existir una sumisión voluntaria al arbitraje, existe una «clara» vulneración del derecho a la tutela judicial

9 Respecto a la incidencia de las directivas y el Derecho de la Unión en la resolución de la cuestión, se postula que la sentencia lleva a cabo, de facto, una interpretación del art. 203 de la Directiva 2009/138/CEE. La interpretación de la normativa comunitaria estaría conferida de forma exclusiva al Tribunal de Justicia de la Unión Europa. Por tanto, si el Tribunal Constitucional tiene alguna duda sobre la interpretación o alcance de las directivas aplicables, la única solución habría sido el planteamiento de una cuestión prejudicial. En cuanto al principio de primacía del Derecho comunitario, se sostiene que este principio no es de carácter general y solo despliega su eficacia respecto a las competencias propias de la Unión y no como un parámetro de enjuiciamiento para analizar la adecuación de una norma al orden constitucional español.

${ }_{10}$ Art. 9 de la Ley de Arbitraje: «1. El convenio arbitral, que podrá adoptar la forma de cláusula incorporada a un contrato o de acuerdo independiente, deberá expresar la voluntad de las partes de someter a arbitraje todas o algunas de las controversias que hayan surgido o puedan surgir respecto de una determinada relación jurídica, contractual o no contractual. 2. Si el convenio arbitral está contenido en un contrato de adhesión, la validez de dicho convenio y su interpretación se regirán por lo dispuesto en las normas aplicables a ese tipo de contrato». 
efectiva. Sin embargo, el magistrado entiende que esta limitación del derecho fundamental de la aseguradora estaría justificada con base en el art. 51 $\mathrm{CE}$ al encontrarnos ante un contrato de adhesión en el que existe un inicial desequilibrio en las posiciones contractuales de las partes. Por tanto, el art. 73.e) LCS y la consiguiente limitación al derecho de la aseguradora es una medida que persigue un fin constitucionalmente legítimo, que es adecuada y proporcionada, por lo que entiende que la cuestión debía desestimarse y el precepto declarado adecuado a la Constitución.

\section{ALGUNAS REFLEXIONES ACERCA DE LA STC 1/2018}

\section{El anclaje constitucional del arbitraje en el ordenamiento jurídico español: la autonomía de la voluntad como fundamento de la institución arbitral}

El arbitraje es una institución que encuentra su fundamento en la autonomía de la voluntad de las partes como manifestación de la dignidad de la persona y el libre desarrollo de su personalidad (art. $10 \mathrm{CE}$ ) y en la libertad como valor superior del ordenamiento jurídico (art. 1 CE). Esta es la concepción de la naturaleza del arbitraje que se impone en la sentencia.

En su voto particular, el magistrado Xiol Ríos empieza criticando que la institución arbitral se considere un «equivalente jurisdiccional», ya que este no tiene su asiento en el art. $24 \mathrm{CE}$, sino en el art. $10 \mathrm{CE}^{11}$. Sin embargo, la equivalencia jurisdiccional del arbitraje, tal como debe ser entendida en la actualidad, se predica respecto a sus efectos — «una decisión al conflicto con efectos de cosa juzgada»- y no en cuanto a su naturaleza. La sentencia que comentamos no asienta la institución arbitral en el art. $24 \mathrm{CE}$. De hecho, se concibe el arbitraje como una renuncia «expresa y puntual» al ejercicio del derecho a la tutela judicial efectiva. No podría basarse una institución en un derecho al que se renuncia para acceder a ella. En este caso, la vulneración del art. $24 \mathrm{CE}$ se produce no por ser este el fundamento del arbitraje a cuyo sometimiento obliga la norma, sino por la exclusión de la jurisdicción ordinaria que el propio sistema arbitral conlleva. Basta una lectura atenta de la resolución para comprobar que la pro-

${ }^{11}$ En términos similares se manifestó el magistrado J. A. XIOL Ríos en «El arbitraje en la Constitución», en J. C. FERnÁndez RozAs (coord.), Veinticinco años de arbitraje en España, Madrid, CIMA, Corte Civil y Mercantil de Arbitraje, 2015, pp. 51-56. 
pia sentencia adopta la concepción ius privatista y contractualista del arbitraje que el magistrado defiende ${ }^{12}$.

Por esta razón, el propio TC ha sostenido que el derecho a la imparcialidad del árbitro o o la prohibición de indefensión en la sustanciación del arbitraje son «derechos subjetivos» que derivan de la configuración legal del arbitraje. Así, se concluye que estos derechos «no son garantías derivadas - con el carácter de derechos fundamentales-del art. $24 \mathrm{CE}{ }^{13}$, sino garantías de legalidad ordinaria derivadas de la Ley de Arbitraje que cuentan con un cauce de tutela específico: la acción de anulación. Y es que, si el arbitraje conlleva una renuncia puntual al ejercicio del derecho a la tutela judicial efectiva, difícilmente los derechos y garantías que forman parte de este se proyectarán sobre el procedimiento arbitral.

Dicho esto, son esta libertad y autonomía de la voluntad las que justifican constitucionalmente la renuncia «expresa y puntual» al ejercicio del

${ }_{12}$ Sentencia 1/2018, FJ 3: «Hay que subrayar, como se ha hecho en anteriores ocasiones, que el arbitraje, en cuanto equivalente jurisdiccional, se sustenta en la autonomía de la voluntad de las partes plasmada en el convenio arbitral. Es "un medio heterónomo de arreglo de controversias que se fundamenta en la autonomía de la voluntad de los sujetos privados" (art. 1.1 CE)» (STC 176/1996, de 11 de noviembre, FJ 1). Dicha sentencia, en su FJ 4, resalta la importancia de la nota de voluntariedad en el arbitraje: «Lo que constitucionalmente le vincula con la libertad como valor superior del ordenamiento (art. 1.1 CE). De manera que no cabe entender que, por el hecho de someter voluntariamente determinada cuestión litigiosa al arbitraje de un tercero, quede menoscabado y padezca el derecho a la tutela judicial efectiva que la Constitución reconoce a todos» (la cursiva es nuestra).

Por tanto, el arbitraje obligatorio no menoscabaría el derecho a la tutela judicial efectiva por ser una manifestación o «sucedáneo» de la jurisdicción ordinaria, sino simplemente porque su imposición supone una renuncia puntual al ejercicio de este no amparada en la libre voluntad de la persona como manifestación de su libre desarrollo de la personalidad (art. 10 CE).

13 STC 9/2015, de 17 de enero, FJ 5: «Es indudable que quienes someten sus controversias a un arbitraje de equidad tienen un derecho subjetivo a la imparcialidad del árbitro [art. 12.3 de la Ley de Arbitraje de 1988 (RCL 1988, 2430, y RCL 1989, 1783) y art. 17 de la Ley 60/2003, de 23 de diciembre, de Arbitraje (RCL 2003, 3010)] y a que no se les cause indefensión en la sustanciación de las actuaciones arbitrales (art. 21.1 de la Ley de Arbitraje de 1988 y art. 24.1 de la Ley de Arbitraje de 2003), derechos que derivan de la misma configuración legal del arbitraje como forma de heterocomposición de los conflictos entre ellos. Pero esos derechos tienen precisamente el carácter de derechos que se desenvuelven en el ámbito de la legalidad ordinaria y que se tutelan, en su caso, a través del recurso o acción de anulación que la regulación legal del arbitraje — por medio de motivos de impugnación tasados - concede a quienes consideren que aquellos han sido vulnerados. Como ya se ha expuesto, sin embargo, la imparcialidad del árbitro y la probibición de indefensión en el arbitraje no son garantías derivadas - con el carácter de derechos fundamentales - del art. 24 CE, cuyas exigencias solo rigen, en lo que atañe ahora a las concretas alegaciones que se están examinando, para el proceso - actuaciones jurisdiccionales - en el que se pretende la anulación del laudo y para el órgano judicial que lo resuelve» (la cursiva es nuestra). 
derecho a la tutela judicial efectiva. Esto es así ya que, pese a que pueda parecer contradictorio, el TC sostiene que el derecho a la tutela judicial efectiva es irrenunciable e indisponible. Lo que es renunciable por la partes es un ejercicio «determinado» o «puntual». Además, la sentencia sostiene que esta renuncia determinada al ejercicio del derecho debe ser «explícita, clara, determinante e inequívoca» ${ }^{14}$. Desde luego, cabría cuestionarse sobre el ámbito o grado de determinación que debe cumplir la renuncia al ejercicio concreto del derecho a la tutela judicial efectiva, así como la relevancia constitucional de los requisitos necesarios para que la misma sea admisible; se trata, sin embargo, de cuestiones que desbordarían por completo el objeto de este comentario.

Como consecuencia de lo anterior, el Tribunal concluye que, en abstracto, el arbitraje solo es constitucionalmente admisible cuando: $i$ ) es fruto del concurso de voluntades de ambas partes del pleito o ii) cuando, siendo obligatorio, el ordenamiento jurídico contempla algún tipo de control judicial sobre el fondo del asunto.

\section{La imposibilidad de control judicial sobre el fondo del laudo arbitral y, en concreto, del orden público como motivo de anulación}

Esta última conclusión es una de las principales afirmaciones criticables de la sentencia que no deja de ser contradictoria con la esencia misma del arbitraje. Para llegar a ella el Tribunal pone en relación dos premisas: que el arbitraje supone una renuncia puntual al ejercicio del derecho a la tutela judicial efectiva y que la acción de anulación del laudo arbitral regulada en los arts. 40 y ss. de la Ley de Arbitraje se circunscribe únicamente a un mero juicio externo de validez del laudo arbitral. Por ello, la única posibilidad de adecuar constitucionalmente un arbitraje obligatorio a los principios constitucionales sería prever un control judicial sobre el fondo del laudo.

Como es bien sabido, el único caso en que se permite una revisión sobre el fondo del laudo arbitral es la contravención del orden público previsto como motivo de anulación en el art. 41.1.f) de la Ley de Arbitraje. Por ello, se muestra de especial interés para nuestro estudio analizar qué

${ }^{14}$ Pese a que el Tribunal Constitucional no lo diga expresamente, es imposible no realizar un paralelismo con los requisitos que jurisprudencialmente se han fijado por parte de la Sala Primera del Tribunal Supremo para considerar válida la renuncia de derechos conforme al art. 6 del Código Civil. 
debe entenderse por orden público y hasta qué extremo permite la revisión sobre el fondo del laudo arbitral ${ }^{15}$.

No podemos dejar de señalar que en la actualidad, y como consecuencia de una serie de resoluciones de la Sala de lo Civil y Penal del TSJ de Madrid $^{16,17}$, ha resurgido el interés — si es que en algún momento desapareció- por parte de la doctrina en delimitar el concepto de orden público. Esta tarea tiene la finalidad de poner coto a estas líneas jurisprudenciales que, en un intento de ampliar el concepto de orden público como motivo de anulación del laudo más allá de sus límites, generan el riesgo de crear un mecanismo genérico y abierto de impugnación que convertiría la acción de anulación en un auténtico recurso de apelación ${ }^{18,19}$. De esta manera, se

15 Para un estudio del concepto de orden público en más de cuarenta jurisdicciones a nivel internacional vid. el estudio Recognition and Enforcement of Arbitral Awards: Study on Public Policy, elaborado por el Subcommittee on Recognition and Enforcement of Arbitral Awards de la International Bar Association, 2015, disponible en https://www.ibanet.org/.

16 SSTSJ de Madrid 13/2015, de 28 de enero; 30/2015 y 31/2015, de 14 de abril; $74 / 2015$, de 23 de octubre, y 83/2015, de 17 de noviembre, entre otras.

17 Respecto a esta línea jurisprudencial del TSJ de Madrid varios autores han señalado que se aprecia «una deriva provocada por una serie de resoluciones recientes, de técnica harto discutible, en cuanto empeñadas — como denominador común — en desbordar sistemáticamente los estrictos límites formales en los que la intervención judicial debe desenvolverse y optar, en consecuencia, por adentrarse en terrenos sustantivos, ignotos y vedados a su conocimiento, por expresa disposición legislativa». Vid. G. STAMPA CASAS, «Hacia un rumbo incierto en el control judicial del arbitraje (comentario a la Sentencia de la Sala de lo Civil y Penal del Tribunal Superior de Justicia de Madrid de 28 de enero)», Revista de Arbitraje Comercial y de Inversiones, vol. 8, núm. 2 (2015), pp. 547-552. En el mismo sentido se ha señalado que: «El TSJ de Madrid, en sentencias como estas, está impartiendo justicia en el caso concreto, yendo en contra de lo que fue la voluntad de las partes y dejándose llevar por un cierto perjuicio anti arbitral». Vid. J. AlmogUERA, «El oportunismo en la acción de anulación del laudo», en G. JimÉnez Blanco (coord.), Anuario de arbitraje 2016, Pamplona, Aranzadi, 2016, pp. 94. Asimismo, se ha afirmado que: «La importancia del control jurisdiccional, dentro de unos límites desglosados de la práctica, ha sido puesta de relieve por la jurisprudencia española, que se ha movido en esta materia con carácter ejemplar hasta la fecha [...]. Sin embargo, este panorama ha contado desde el año 2015 con un parecer discrepante que ha quebrado los principios consolidados de mínima intervención, del carácter no automáticamente excluyente de orden público y de no revisión del fondo del laudo». Vid. J. C. FERnÁNDEZ RozAs, «Contravención al orden público como motivo de anulación del laudo arbitral en la reciente jurisprudencia española», Revista de Arbitraje Comercial y de Inversiones, vol. 8, núm. 3 (2015), pp. 850.

${ }_{18}$ Según la propia exposición de motivos de la Ley de Arbitraje: «Respecto de la anulación, se evita la expresión "recurso" por resultar técnicamente incorrecta. Lo que se inicia con la acción de anulación es un proceso de impugnación de la validez del laudo. Se sigue partiendo de la base de que los motivos de anulación del laudo han de ser tasados y no ban de permitir, como regla general, una revisión del fondo de la decisión de los árbitros».

19 Para un estudio del concepto de orden público como motivo de anulación del laudo arbitral vid. J. Remón PeÑalver, «Orden público y acción de anulación», en M. J. MenÉNDEZ ArIas (coord.), Anuario de arbitraje 2017, Pamplona, Aranzadi, 2017, pp. 405-423. En este 
muestra de vital importancia para la seguridad jurídica en el tráfico económico, para la protección de la institución arbitral y para la promoción del arbitraje como medio idóneo de resolución de conflictos intentar definir claramente el contenido del único motivo que permitiría la revisión sobre el fondo del laudo ${ }^{20}$.

Para algunos autores —entre los que se encuentra el magistrado Xiol Ríos- el orden público debe ser interpretado restrictivamente e identificarse únicamente con el respeto «de los derechos fundamentales y a los valores y principios esenciales indisponibles para el legislador por exigencia de la Constitución» ${ }^{21,22}$. Esta postura vendría respaldada por algu-

estudio, el autor postula que: «La acción de anulación no puede convertirse en un recurso de apelación, no es un cauce para la revisión judicial de la decisión arbitral de fondo porque el respeto a la autonomía de la voluntad de las partes impide que a través del juicio de anulación pueda sustituirse la decisión de los árbitros por los jueces. Ese límite al alcance de la acción de anulación viene impuesto por el respeto a la autonomía de la voluntad y no puede sortearse mediante la ampliación del concepto de orden público como motivo de anulación» (p. 413).

${ }^{20}$ La doctrina científica ha señalado que: «Con la imposibilidad de revisión de fondo por el juez se garantiza el respeto a la autonomía de la institución arbitral dando sentido al funcionamiento de dicho principio y garantizando el respeto al efecto de cosa juzgada del laudo sobre la base del respeto por lo decidido por el árbitro. Su falta de acatamiento podría provocar la desconfianza de las partes, que recurren al arbitraje en la desnaturalización de la institución mediante una intervención judicial demasiado agresiva». Vid. J. C. FERNÁNDEZ RozAS, «Riesgo de la heterodoxia en el control judicial de los laudos arbitrales», La Ley. Revista Jurídica Española de Doctrina, Jurisprudencia y Bibliografía, núm. 8537 (2015).

${ }^{21}$ J. A. Xiol Ríos, en C. GonzÁlez-Bueno (dir.), Comentarios a la Ley de Arbitraje, Madrid, Consejo General del Notariado, 2014, p. 834.

22 Para Fernández Rozas: «La infracción del orden público no puede comprender cualquier infracción de una norma jurídica, aunque se trate de norma imperativa, ya que no toda infracción de norma imperativa es cuestión del orden público, y así, el matiz en que se concreta es que la contravención solo será procedente cuando el árbitro haya pronunciado su laudo con evidente infracción de los derechos fundamentales, atendiendo a la normativa procedimental aplicable». Vid. J. C. FERnÁNDEZ RozAS, «Contravención al orden público...», op. cit., p. 830. Barona Vilar entiende que: «Tomando como punto de partida la referencia que en la legislación arbitral se realizaba del mismo (orden público) interpretado desde los principios que rigen nuestra Constitución, cuyo intérprete máximo no puede ser otro que el Tribunal Constitucional, con arreglo a cuyas declaraciones debemos entender que para que un laudo arbitral sea atentatorio al orden público será preciso que vulnere los derechos y libertades fundamentales reconocidos en el capítulo II del título I de nuestra Constitución garantizados a través de lo dispuesto en términos de generalidad por el art. 24 de la misma [...]. La infracción del orden público no puede asimilarse a cualquier infracción de una norma jurídica, ni siquiera a infracción de norma imperativa, ya que no toda infracción de norma imperativa es cuestión de orden público, como tampoco cualquier infracción de los principios de justicia y equidad puede equipararse a infracción del orden público, sino tan solo la conculcación de aquellos principios de justicia y equidad que conforman el concepto de orden público constitucional». Vid. S. Barona VILAR (coord.), Comentarios a la Ley de Arbitraje, 2. ${ }^{a}$ ed., Pamplona, Aranzadi, 2011, pp. 17467. En la misma línea Almoguera sos- 
nas resoluciones del propio TC recaídas en procedimientos de exequatur de sentencias extranjeras ${ }^{23}$. Por ello, y en sintonía con la concepción del arbitraje que defendemos y creemos que adopta la resolución que comentamos, se ha llegado a sostener que no se puede hablar propiamente de «orden público procesal»; esto es, de incorporar dentro del concepto de orden público como motivo de anulación del laudo las garantías procesales contempladas en la Ley de Arbitraje. Y esto es así ya que, si el orden público se identifica principalmente con los derechos fundamentales $y$, como hemos defendido más arriba, las garantías procesales del procedimiento arbitral tienen su causa y fundamento en la legislación ordinaria $-\mathrm{y}$ no en el derecho fundamental al cual se renuncia para acceder a la institución-, no existiría propiamente tal concepto y la tutela de estas garantías se obtendría a través de otros motivos de anulación [art. 41.1.b)] ${ }^{24}$.

Para otro sector de la doctrina no puede admitirse un concepto de orden público que se identifique únicamente con el respeto de los derechos y libertades fundamentales reconocidos constitucionalmente. Para apoyar esta posición se afirma que el propio Tribunal de Justicia de la Unión Europea ha sostenido la necesidad de ampliar la noción de orden público para proteger otras parcelas del ordenamiento jurídico. Así, en

tiene que: «Para interferir solo lo imprescindible en la autonomía de la voluntad de las partes, el concepto de orden público que opera como límite del arbitraje debe ser sumamente restrictivo, y está pacíficamente aceptado por la doctrina y los tribunales judiciales que la infracción del orden público debe limitarse a la infracción de derechos fundamentales o libertades públicas constitucionalmente protegidos». Vid. J. AlmogUERA, «El oportunismo en la acción de anulación del laudo», en G. JiméNEz BlANCO (coord.), Anuario de arbitraje 2016, Pamplona, Aranzadi, 2016, pp. 91-92. Para Álvarez Sánchez de Movellán, de lege data: «La admisibilidad del recurso de anulación del laudo arbitral, por ser este contrario al orden público, estará condicionada a que dicha vulneración haga referencia a alguno de los derechos fundamentales mencionados en el art. 53.2 de la Constitución». Vid. P. Álvarez SÁNCHEZ DE Movellan, La anulación del laudo arbitral. El proceso arbitral y su impugnación, Granada, Comares, 1996, pp. 370-371.

23 Por ejemplo, STC 43/1986, de 15 de abril (FJ 4).

${ }^{24}$ J. Remón PeÑAlver, «Orden público y acción...», op. cit., p. 416. En el mismo sentido Claros Alegría afirma: «A nuestro modo de ver, la referencia al orden público procesal ampara todavía un uso recurrente, demasiado amplio y poco técnico, ante nuestros tribunales de esta causa de nulidad, llegándose a estimar anulaciones de dudosa cabida bajo este concepto o que en realidad corresponden a otras causas de anulación (infracción del procedimiento arbitral). Consideramos que la esencia de las garantías procesales de nuestro ordenamiento (art. $24 \mathrm{CE}$ ), en lo que puedan tener de aplicables al proceso arbitral, tendrán su adecuada salvaguarda en la causa de anulación de las letras $b$ ) o d) del art. 41.1 de la nueva Ley de Arbitraje, por lo que este motivo de contravención del orden público debería quedar reservado en puridad para cuestiones de índole material». Vid. P. Claros Alegría, en R. Hinojosa Segovia (coord.), Comentarios a la Ley de Arbitraje, 2. ${ }^{a}$ ed., Madrid, Difusión Jurídica y Temas de Actualidad, 2008, pp. 259-261. 
la STJUE de 1 de junio de 1999 (asunto C-129/97), el Tribunal impondría la necesidad de considerar contrarios al orden público aquellos laudos que vulneren las normas del derecho de la competencia (el actual art. 101 TFUE) ${ }^{25}$. Para Ormazábal Sánchez, el concepto de orden público tendría que integrarse por ciertas previsiones de carácter imperativo que, no pudiendo ser excluidas por voluntad de las partes, producen un efecto lesivo para el interés general ${ }^{26,27}$. Para ello, y negando cualquier equiparación automática entre norma imperativa y orden público, el autor propone acudir al concepto de «leyes de policía» contemplado, entre otros textos normativos comunitarios, el art. 9 del Reglamento (CE) núm. 593/2008, de 17 de junio (Roma I) ${ }^{28}$, como una pauta útil para delimitar el concepto de orden público ${ }^{29}$. Así, el orden público estaría integrado por aquellas «normas ordopolíticas o de dirección que tienen por finalidad proteger las políticas económicas y el mercado de un determinado Estado (normas sobre el control de cambios, libre competencia, seguridad y salud pública, etc.) y normas de protección que atenderían más directamente a garantizar el equilibrio contractual del contrato y, en este sentido, estarían fundadas en un interés más privado (normas sobre condiciones generales de la contratación, protección del consumidor, trabajador asegurador, etc.)» ${ }^{30}$.

En todo caso, con independencia del concepto de orden público que se defienda, resulta claro que este no puede concebirse como un mecanismo genérico que permita una revisión general sobre el fondo del laudo arbitral. Por lo cual, y volviendo al tema que nos ocupa, la mera posibilidad con-

25 STJUE de 1 de junio de 1999, asunto C-129/97, párrafo 44: «Un órgano jurisdiccional nacional al que se ha presentado un recurso de anulación de un laudo arbitral debe estimarlo cuando considere que el laudo es efectivamente contrario al art. $81 \mathrm{CE}$, si conforme a las normas procesales internas debe estimar un recurso de anulación basado en el incumplimiento de normas nacionales de orden público».

26 G. Ormazábal SÁnchez, El control judicial sobre el fondo del laudo, Madrid, Marcial Pons, 2017, p. 83.

${ }_{27}$ Para Ormazábal Sánchez sería inapropiado intentar desprender un concepto de orden público de las resoluciones dictadas por el Tribunal Constitucional, ya que este órgano constitucional tendría el cometido de resolver, únicamente, «sobre la dimensión constitucional del orden público» (ibid., p. 73).

${ }^{28}$ Reglamento (CE) núm. 593/2008, de 17 de junio (Roma I), art. 9: «1. Una ley de policía es una disposición cuya observancia un país considera esencial para la salvaguardia de sus intereses públicos, tales como su organización política, social o económica, hasta el punto de exigir su aplicación a toda situación comprendida dentro de su ámbito de aplicación, cualquiera que fuese la ley aplicable al contrato según el presente Reglamento».

${ }_{29}$ G. OrmazÁBAL SÁnchez, El control judicial sobre el fondo..., op. cit., p. 86.

30 J. C. Férnandez Rozas y S. SÁnchez LoRenzo, Derecho internacional privado, 9. a ed., Pamplona, Aranzadi, p. 597, citado en G. OrmazÁbal SÁnCHEZ, El control judicial sobre el fondo..., op. cit., p. 88. 
templada por el Tribunal Constitucional en la sentencia que comentamos de admitir un control del laudo arbitral sobre el fondo del asunto es una idea totalmente incompatible con la esencia misma de la institución arbitral y con los principios sobre los que se asienta a nivel internacional. Si se permitiera cualquier tipo de revisión sobre el fondo del asunto, el interés de las partes de someter su disputa al conocimiento de un árbitro - y, por tanto, de excluir el conocimiento de su controversia a la jurisdicción ordinariaquedaría totalmente debilitado. La funcionalidad y eficacia práctica del arbitraje se fundamentan, justamente, en su concepción como un mecanismo que permite zanjar de forma definitiva y heterónoma las disputas existentes entre las partes que se someten a él. Esta finalidad se consigue impidiendo la revisión sobre el fondo del laudo arbitral y dotándole de efectos de cosa juzgada (art. 43 de la Ley de Arbitraje). Por esta razón, será estéril cualquier intento de localizar las normas procesales concretas que impidan la revisión sobre el fondo del asunto, como postula el magistrado Valdés Dal-Ré en su voto particular, ya que en ese caso, como acertadamente apunta el magistrado Xiol Ríos en el suyo, «lo inconstitucional no sería el art. 76.e) LCS, sino, en general, todo el procedimiento arbitral».

En definitiva, si se admitiera cualquier tipo de recurso jurisdiccional que permitiera la revisión del fondo del asunto, el arbitraje perdería parte de su esencia y quedaría totalmente desnaturalizado. Por ello, la argumentación realizada en este extremo por el Tribunal, que no es más que una reiteración automática de la jurisprudencia constitucional anterior (SSTC 174/1995, de 23 de noviembre; 352/2006, de 14 de diciembre; $119 / 2014$, de 16 de julio, y 8/2015, de 22 de enero), opera más bien como una mera posibilidad abstracta que no está contemplada en nuestro ordenamiento jurídico y que, en todo caso, se situaría al margen de los principios básicos que rigen la institución arbitral. Además, el afirmar que solo es posible el arbitraje obligatorio si se permite un posterior control judicial sobre el fondo del asunto es tautológico. En ese caso, no se impondría ninguna renuncia puntual al ejercicio del derecho de acceso a la jurisdicción, por cuanto siempre sería posible acudir a ella y el arbitraje se impondría como un mero requisito de procedibilidad.

Descartada la segunda posibilidad propuesta por el Tribunal (es decir, prever un control judicial del laudo sobre el fondo), podemos afirmar que el arbitraje será constitucionalmente admisible —como renuncia puntual al ejercicio del derecho a la tutela judicial efectiva - únicamente cuando sea fruto de un concurso de voluntades entre las partes. 


\section{La ponderación de los derechos e intereses en conflicto: el derecho a la tutela judicial efectiva versus la protección de los consumidores y usuarios}

Si trasladamos lo anteriormente expuesto al análisis concreto del precepto cuya constitucionalidad se analiza en la sentencia que comentamos, podemos concluir, sin necesidad de mayores argumentaciones, que el art. 73.e) LCS vulnera el derecho a la tutela judicial efectiva de la entidad aseguradora en tanto que permite al asegurado someter unilateralmente a arbitraje una disputa surgida entre ambos sin el consentimiento de la primera. Es la falta del concurso de voluntades - fundamento constitucional de la institución arbitral- lo que genera la vulneración del art. 24 CE. Y esta vulneración se lleva a cabo no porque el arbitraje se sustente en el art. $24 \mathrm{CE}$, sino porque, al obligar a la entidad aseguradora a someterse a él, se excluye la posibilidad de que acuda a la jurisdicción ordinaria. Esto es, la vulneración del derecho fundamental vendría dada no por la naturaleza de la institución a la que se le somete, sino por la exclusión que la misma conlleva. De una lectura atenta de la resolución podrá comprobarse que, con algunos matices, esta es una conclusión compartida tanto por la mayoría como por los magistrados que formularon su voto particular.

Una vez que constatamos que el art. 73.e) LCS limita el derecho a la tutela judicial efectiva de la aseguradora cabe plantearse si existe alguna razón que constitucionalmente la justifique. Aquí reside, en esencia, la cuestión controvertida que mantuvo enfrentada a la mayoría con la minoría plasmada en los votos particulares. En última instancia, la constitucionalidad del art. 73.e) LCS dependerá de la existencia de una justificación constitucional a la limitación del art. $24 \mathrm{CE}$ que padece la entidad aseguradora.

A este respecto, el Tribunal Constitucional entiende que la previsión del art. 73.e) LCS no puede considerarse como un obstáculo arbitrario o caprichoso al ejercicio del derecho, pues tiene como finalidad fomentar el arbitraje y otorgar una especial protección al asegurado como parte débil del contrato «en su condición de consumidor». Sin embargo, concluye que estos fines - constitucionalmente legítimos- no justifican la restricción al derecho fundamental que conlleva el precepto.

Por el contrario, tanto el magistrado Xiol Ríos como los magistrados Narváez Rodríguez y Enríquez Sancho entienden en sus votos particulares que la protección del consumidor como parte débil del contrato y como bien jurídico constitucionalmente protegido (art. $51 \mathrm{CE}$ ) justificaría 
la limitación al derecho a la tutela judicial efectiva de la aseguradora que el art. 73.e) LCS conlleva. Creemos que estas conclusiones son entendibles pero incorrectas en los términos en que se plantean-o, por lo menos, con la generalidad con que se formulan-.

El derecho a la tutela judicial efectiva, como cualquier otro derecho fundamental, está sometido a unos límites concretos. En general, estos límites suelen clasificarse por la doctrina constitucionalista en límites intrínsecos y extrínsecos. Los primeros se derivan de la propia naturaleza y contenido del derecho. Los segundos se derivan «de la propia existencia social y de los demás sujetos de derecho que en ella existen» ${ }^{31}$, y suelen subclasificarse a su vez en expresos e implícitos en función de si el límite viene impuesto directamente por la Constitución o de si este se infiere de manera indirecta o mediata del texto constitucional ${ }^{32}$. En cuanto a los límites extrínsecos de los derechos fundamentales, el Tribunal Constitucional ha sostenido ya desde su conocida Sentencia 11/1981, de 8 de abril, que los derechos fundamentales podrán ser limitados por su colisión con otros derechos fundamentales (art. $10 \mathrm{CE}$ ) o por su colisión con otros bienes constitucionalmente protegidos ${ }^{33}$.

De lo anterior se concluye que la limitación del derecho a la tutela judicial efectiva que conlleva el art. 73.e) LCS solo podría ser justificada si se basa en otro derecho fundamental o bien jurídico protegido. Tanto en la sentencia como en los votos particulares indicados - con distinto resultado en su ponderación - se presenta la defensa de los consumidores y usuarios como ese bien jurídico constitucionalmente protegido que justificaría la limitación del derecho de la aseguradora ${ }^{34}$. Consideramos, sin embargo, que esta apreciación no es del todo correcta.

31 F. Fernández Segado, El sistema constitucional español, Madrid, Dykinson, 1992, p. 170.

32 P. Pérez Tremps, J. García Morillo et al., Derecho constitucional, vol. 1, 16. ${ }^{a}$ ed., Valencia, Tirant lo Blanch, 2016, pp. 118-120.

33 STC 11/1981, de 8 de abril, FJ 7: «Tampoco puede aceptarse la tesis del recurso de que los derechos reconocidos o consagrados por la Constitución solo pueden quedar acotados en virtud de los límites de la propia Constitución o por la necesaria acomodación con el ejercicio de otros derechos reconocidos y declarados igualmente por la norma fundamental [...]. La Constitución establece por sí misma los límites de los derechos fundamentales en algunas ocasiones. En otras ocasiones el límite del derecho deriva de la Constitución solo de una manera mediata o indirecta, en cuanto que ha de justificarse por la necesidad de proteger o preservar no solo otros derechos constitucionales, sino también otros bienes constitucionales protegidos» (la cursiva es nuestra).

${ }^{34}$ En el texto de la sentencia (FJ 4) puede leerse que se analiza la «especial protección del asegurado en su condición de consumidor». Más oportuno y sensato nos parece el voto particular de Narváez Rodríguez que señala: «El perfil general del asegurado resulta coin- 
Ninguna duda cabe de que el asegurado es la parte débil del contrato. Por esta razón, toda la legislación en la materia, y, por consiguiente, también la LCS, está concebida como una herramienta tuitiva para protegerle. Sin embargo, no compartimos el salto lógico de considerar que, por ser la parte débil del contrato, deba considerársele consumidor en todo caso - con independencia del concepto constitucional o legal que del mismo se maneje- En abstracto, nada impide que un empresario o sociedad en el ámbito de su actividad profesional suscriban un contrato de seguro de asistencia de defensa jurídica con una entidad aseguradora ${ }^{35}$. Un ejemplo alejado de la cuestión que nos ocupa puede ayudarnos a comprobarlo. La Ley 12/1992, de 27 de mayo, sobre contrato de agencia, entiende que el agente es la parte débil del contrato y, en sintonía con esta concepción, efectúa una regulación protectora de su posición contractual. No obstante, eso no significa que deba considerarse al agente como consumidor ${ }^{36}$.

Tampoco nos parece convincente el inferir la condición de consumidor del asegurado por la existencia de un contrato de adhesión. Los contratos de adhesión son una realidad contractual que, como bien se indica, están caracterizados por su preredacción y por la falta de capacidad negocial de alguna de las partes. Sin embargo, es una realidad contractual que no se circunscribe única y exclusivamente a la contratación con consumidores y usuarios.

Dicho lo cual sostenemos que, por lógica y coherencia, si como proponen los votos particulares de los magistrados Xiol Ríos, Narváez Rodríguez y Enríquez Sancho fuera admisible la limitación del derecho a la tutela judicial efectiva de la aseguradora en pro de la defensa de los consumidores como bien jurídico protegido (art. $51 \mathrm{CE}$ ), debería defenderse la constitucionalidad del precepto única y exclusivamente en aquellos casos en los que el asegurado sea efectivamente un consumidor - y no en el resto de supuestos en los que no concurra el supuesto elemento legitimador de la limitación del art. 24 CE-.

cidente con el de un consumidor» o que «los adherentes, generalmente consumidores» (la cursiva es nuestra).

35 El lector podrá analizar las normativa comunitaria transpuesta en la LCS y podrá comprobar que la única referencia al término consumidor en las Directivas 88/357/CEE, 87/344/CEE y 2009/138/CEE se produce en el considerando 79 de esta última para hacer una vaga referencia a la necesidad de que los consumidores reciban «toda la información que precisen antes de la celebración del contrato y durante todo el periodo de vigencia del mismo, de forma que puedan elegir el contrato que mejor se adapte a sus necesidades».

${ }^{36}$ Esta concepción del agente como parte débil del contrato se manifiesta en el carácter imperativo de la mayoría de la ley, en los derechos que en la misma se le confieren o, sin ir más lejos, en la limitación a cualquier pacto de sumisión territorial contemplada en la disposición adicional segunda. 
En todo caso, y aunque no nos pronunciaremos sobre la concreta ponderación de los derechos e intereses en juego, debe advertirse que el resultado del juicio de proporcionalidad realizado por los magistrados en los votos particulares tiene como base una serie de valoraciones y premisas que al plantearse con carácter general también se vuelven inapropiadas para sustentar la conclusión que de forma implícita alcanzan: el sometimiento del conflicto a arbitraje siempre es más beneficioso para el consumidor que un procedimiento judicial. Para ello se basan en la idea de que el arbitraje es un instrumento ágil, rápido, económico o de bajo coste ${ }^{37}$.

El arbitraje es un mecanismo de resolución de conflictos eficaz que, en multitud de ocasiones, se muestra como el medio idóneo para revolver los conflictos surgidos entre las partes de un contrato. Decir lo contrario sería absurdo y un manifiesto desconocimiento de la realidad social actual. Por tanto, nuestra crítica no se dirige a negar los atributos que del arbitraje se profesan, sino de elevarlos a un nivel categórico que los convierta en caracteres propios de la institución arbitral. No puede negarse que la decisión de las partes de someter una disputa a arbitraje depende de varios factores: el carácter nacional o internacional de la controversia; la especialidad o complejidad de la materia sobre la que se proyecta el conflicto; la confidencialidad del procedimiento; la cuantía o importancia económica del pleito, entre otras circunstancias. Y, por tanto, la agilidad, rapidez o economía, en definitiva, la oportunidad de someter una disputa a arbitraje, dependerá de varias circunstancias. Por ello, consideramos inapropiado afirmar que el arbitraje es siempre más barato y rápido que la jurisdicción ordinaria. Esto no es más que la repetición de una serie de tópicos que, en muchas ocasiones, no se ajustan a la realidad. Además, debe advertirse que el asunto del que derivó el planteamiento de la cuestión no procedía de un arbitraje de consumo - cuya gratuidad se impone reglamentariamente -38 , sino ante un arbitraje ordinario ${ }^{39}$.

37 Así, se sostiene que el arbitraje es «un medio ágil y económico» que responde a la necesidad de contemplar «cauces sencillos, rápidos y gratuitos o de escaso coste» (voto particular del magistrado Xiol Ríos) o «un instrumento ágil y rápido» (voto particular del magistrado Narváez Rodríguez).

${ }^{38} \mathrm{El}$ sistema arbitral de consumo está contemplado en los arts. 57 y 58 del Texto Refundido de la Ley General para la Defensa de los Consumidores y Usuarios, y desarrollado reglamentariamente por el Real Decreto 231/2008, de 15 de febrero, por el que se regula el Sistema Arbitral de Consumo. El arbitraje de consumo se configura como un mecanismo extrajudicial de resolución de conflictos que, salvo pacto expreso en contrario por las partes, se decide en equidad. La gratuidad del procedimiento se constituye como una de las características principales del mecanismo.

39 En efecto, como ha sido señalado por la doctrina: «La referencia genérica al arbitra- 
Además de lo anterior, existen razones de índole material y procesal que impiden sostener la premisa de que el arbitraje siempre es mejor para el consumidor. El sometimiento de la controversia a arbitraje le priva al consumidor de todas aquellas medidas de protección y tutela dispensadas por el juez nacional que — con independencia de la valoración que de ellas tengamos- le impone la jurisprudencia del TJUE (por ejemplo, la apreciación de oficio de cláusulas abusivas en cualquier momento en que se tengan los elementos de hecho y derecho para ello).

Podría decirse, con razón, que al constituirse el art. 76.e) LCS como un derecho o facultad, el consumidor podría en cada caso valorar y ponderar su interés y decidir, en función de las circunstancias concurrentes, si someter su disputa a arbitraje o a la jurisdicción ordinaria. No negamos este argumento. Lo que rechazamos es que se realice un juicio abstracto de proporcionalidad dirigido a valorar la dimensión objetiva y una posible limitación del derecho a la tutela judicial efectiva con base en una serie de premisas que no son correctas y en una serie de elementos valorativos del arbitraje que no pueden predicarse con la generalidad que se pretende.

En otro orden de ideas, en su voto particular el magistrado Valdés DalRé defiende la limitación del derecho de la aseguradora en la finalidad de proteger a la parte débil del contrato. Para ello expone la (supuesta) contradicción entre la sentencia que ahora comentamos y las SSTC 119/2014 y 8/2015 en las que se declaró conforme a la Constitución el «arbitraje» obligatorio en el ámbito laboral regulado en el art. 82.3 del Estatuto de los Trabajadores. Pues bien, basta una lectura atenta de las referidas resoluciones para constatar cuál fue la ratio decidendi que llevó al Tribunal a declarar conforme a la Constitución el arbitraje obligatorio en aquellos casos.

je abre la posibilidad de que el asegurado pueda escoger entre cualquier de las modalidades que existen en nuestro país. Por tanto, al asegurado le cabe optar por el arbitraje general contenido en la Ley 60/2003, de 23 de diciembre, de Arbitraje, o el de consumo, contemplado en el Real Decreto 231/2008, de 15 de febrero, por el que se regula el Sistema Arbitral de Consumo». Vid. I. González Barrios, en J. A. Badillo Arias (coord.), Ley de Contrato de Seguro, 3. ${ }^{a}$ ed., Pamplona, Aranzadi, 2017, pp. 1403-1404. En el mismo sentido se ha afirmado que: «El "arbitraje" al que se refiere el art. 76.e) LCS puede ser de dos tipos: el específico arbitraje de consumo del capítulo II del título V del libro I (arts. 57 y 58) del Texto Refundido de la Ley General para la Defensa de los Consumidores y Usuarios [...], aprobado por Real Decreto Legislativo 1/2007 sobre el Sistema Arbitral de Consumo, desarrollado por el Real Decreto 231/2008, de 15 de febrero [...], o el genérico arbitraje de la Ley 60/2003. A la vista de la redacción del art. 61 TRLOSSP, parece existir una preferencia legal por el arbitraje de consumo, debido al carácter de consumidor que tiene el asegurado». Vid. A. J. Tapia Hermida, en J. Sánchez Calero (coord.), Ley del Contrato de Seguro, 4. ${ }^{a}$ ed., Pamplona, Aranzadi, 2010, p. 1927. 
El mecanismo previsto en el art. 82.3 del Estatuto de los Trabajadores se declaró conforme al art. 24 CE porque preveía un «control pleno sobre la decisión o laudo» por parte de los jueces y tribunales. Así, el Tribunal basaría su decisión en una de las excepciones expuestas anteriormente que hacen admisible el arbitraje obligatorio. Sin embargo, a poco que se analice detalladamente el mecanismo previsto en el art. 82.3 del Estatuto de los Trabajadores se llegará a la conclusión de que, pese a la denominación legal utilizada, no nos encontramos un arbitraje stricto sensu. Y no lo es porque su finalidad es «procurar una solución extraprocesal», por lo que su naturaleza se acerca más a la institución de la mediación; porque la decisión que se alcance no tiene efectos de cosa juzgada, sino «la eficacia de los acuerdos alcanzados en periodo de consultas»; porque se configura como un «trámite previo al proceso», y, principalmente, porque el fondo del asunto es revisable por la jurisdicción ordinaria al no excluir «el ulterior conocimiento jurisdiccional de la cuestión» ${ }^{40}$.

40 STC 119/2017, de 16 de julio, FJ 5: «A su vez, esa remisión a los motivos y procedimientos establecidos para los convenios colectivos conlleva la posibilidad de impugnación judicial por considerar que la decisión o laudo arbitral "conculca la legalidad vigente o lesiona gravemente el interés de terceros" [art. 163.1 de la Ley de la Jurisdicción Social (RCL 2011, 1845)]. En consecuencia, el conjunto de estas previsiones permite concluir que el art. 82.3 ET, párrafo octavo, somete expresamente la decisión arbitral de la CCNCC o del órgano autonómico correspondiente a un control judicial que no se limita a aspectos externos o procedimentales; se extiende también a aspectos de fondo del asunto objeto de la decisión o arbitraje, pues más allá del enjuiciamiento sobre el cumplimiento de los requisitos y formalidades del desarrollo de la actuación arbitral, así como de la valoración sobre el carácter ultra vires de la resolución emitida, la revisión por parte de los órganos judiciales alcanza también a impugnaciones fundadas no solo en motivos de lesividad a terceros, sino también de ilegalidad, sin establecerse precisiones respecto a esta última causa. A partir de esta regulación normativa no cabe excluir que esa intervención judicial derivada del art. 82.3 LET permita a los tribunales ordinarios efectuar un control pleno sobre la decisión o laudo arbitral en aquellos aspectos jurídicos que, por su naturaleza, puedan ser objeto de la competencia y conocimiento jurisdiccional. Así entendida, por tanto, la intervención de la CCNCC u órgano autonómico correspondiente prevista en la norma impugnada —con carácter subsidiario, como ya se dijo-, en cuanto trámite previo al proceso es plenamente compatible con el art. 24.1 CE; en ningún caso excluye el ulterior conocimiento jurisdiccional de la cuestión y su fin resulta proporcionado y justificado, ya que no es otro que "procurar una solución extraprocesal de la controversia, lo cual resulta beneficioso tanto para las partes, que pueden resolver así de forma más rápida y acomodada a sus intereses el problema, como para el desenvolvimiento del sistema judicial en su conjunto, que ve aliviada su carga de trabajo" [STC 217/1991, de 14 de noviembre (RTC 1991, 217), FJ 6].En definitiva, interpretado el precepto en el sentido de que cabe un control judicial pleno sobre la adecuación normativa de la decisión o laudo arbitral de la CCNCC u órgano equivalente de las Comunidades Autónomas, acotado a los aspectos jurídicos propios del conocimiento de la jurisdicción, incluido el control sobre la concurrencia de las causas y la adecuación a ellas de las medidas adoptadas, hemos de descartar que el párrafo octavo del art. 82.3 LET, en la redacción dada 


\section{El juicio de relevancia y su incidencia en la resolución de la cuestión planteada}

Por otro lado, nos pronunciaremos brevemente sobre el juicio de relevancia realizado por el TSJ de Cataluña en su auto de planteamiento de la cuestión, un extremo sobre el que se posicionan todos los votos particulares. Y lo haremos no desde una perspectiva constitucional como requisito para la admisión de una cuestión de inconstitucionalidad, sino desde una perspectiva material sobre el fondo. Debe advertirse que no disponemos - pese a que hubiera sido deseable - del tenor literal de la póliza de seguro y de todos los elementos de hecho y derecho que nos permitan emitir una conclusión definitiva. En todo caso, consideramos que, tal como se encarga de explicar Narváez Rodríguez en su voto particular, la redacción de la póliza era indispensable para declarar la inconstitucionalidad de la norma.

$\mathrm{El}$ art. 76.e) LCS declarado inconstitucional reconocía el derecho del asegurado a someter a arbitraje las disputas surgidas entre él y la entidad aseguradora en el seno del contrato de seguro de asistencia jurídica. El art. 76.f) LCS impone la obligación de la entidad aseguradora de «recoger expresamente» este derecho. Aquí pueden plantearse dos interpretaciones del término «recoger». La primera es que el derecho del asegurado es un derecho de origen legal y que, por tanto, su inclusión en el contrato es a los meros efectos informativos. La segunda es que el derecho es de origen contractual y que, por tanto, es necesario que sea reconocido en el contrato para que nazca y sea efectivo - esto explicaría la necesidad de establecer en el art. 76.f) expresamente la obligación de la aseguradora de «recogerlo»- . Las consideraciones anteriores, que pueden parecer meras observaciones de índole abstracto o doctrinal, podrían haber llevado a considerar que el art. 73.e) LCS no vulneraba el art. 24 CE de la aseguradora ${ }^{41}$.

por el art. 14.uno de la Ley 3/2012, resulte contrario al derecho a la tutela judicial reconocido en el art. 24.1 CE. Esta interpretación de conformidad se llevará al fallo» (las cursivas son nuestras). En el mismo sentido la STC 8/2015, que se remite a la anteriormente transcrita.

${ }^{41}$ Para entender la cuestión podemos hacer un paralelismo con el derecho de desistimiento reconocido en el Texto Refundido de la Ley de Consumidores y Usuarios. Esta ley se encarga de indicar expresamente en su art. 68 que el derecho es «atribuido legalmente al consumidor». El art. 69, cuya rúbrica resulta ilustrativa por sí misma («obligación de informar sobre el derecho de desistimiento»), determina que: «[C]uando la ley atribuya el derecho de desistimiento al consumidor y usuario, el empresario contratante deberá informarle por escrito en el documento contractual, de manera clara, comprensible y precisa, del dere- 
Si aceptáramos a los meros efectos dialécticos que el derecho nace en el mundo jurídico al ser incorporado por la entidad aseguradora en la póliza, no podríamos decir que existe un arbitraje sin un concurso de voluntades - qué mayor expresión del consentimiento y la autonomía de la voluntad de las partes que la configuración de sus relaciones jurídicas a través un contrato- De esta manera, lo inconstitucional no sería la previsión abstracta del derecho del asegurado [art. 73.e) LCS], sino la obligación legal de la aseguradora de incorporarlo — rectus «recogerlo»- en el contrato [art. 73.f) LCS]. Por tanto, de sostener esta tesis — perfectamente posible y defendible- la cuestión no tendría que haber sido admitida por no superar el juicio de relevancia y, en todo caso, no podría considerarse que el precepto cuestionado vulnera el derecho a la tutela judicial efectiva de la entidad aseguradora, por cuanto el arbitraje sería fruto del consentimiento plasmado por ambas partes en el contrato de seguro de asistencia jurídica.

\section{El Derecho comunitario como parámetro de enjuiciamiento de la constitucionalidad del art. 73.e) LCS}

Por último, nos gustaría apuntar que sería estéril cualquier discusión sobre si el art. 73.e) LCS transponía de forma correcta la normativa comunitaria. Para ello habría que responder, entre otras, a las siguientes preguntas: ¿las Directivas 87/344/CEE, 88/357/CEE y 2009/138/CEE conceden un derecho unilateral al asegurado de someter la disputa a arbitraje? ¿Qué características debe tener el «procedimiento arbitral u otro procedimiento» análogo previsto por la legislación nacional? ¿El laudo arbitral que se dicte debe tener efectos de cosa juzgada conforme al art. 43 de la Ley de Arbitraje? ¿Qué características debe tener ese «recurso a una instancia jurisdiccional» que se contemple? Si el TSJ de Cataluña tenía estas dudas tendría que haberlas planteado al único órgano que les puede dar respuesta: el TJUE. En todo caso, el hecho de que el art. 73.e) LCS transpusiera de forma correcta las directivas tampoco tendría que haber cambiado las conclusiones alcanzadas por el TC.

Es incuestionable que las directivas dan un amplio margen al legislador nacional para regular, en este caso, el derecho del asegurado de someter la

cho de desistir del contrato y de los requisitos y consecuencias de su ejercicio». De lo anterior, podemos concluir, sin ningún género de dudas, que el derecho de desistimiento es un derecho legal que nace con independencia de su inclusión en el contrato. 
disputa a arbitraje o - no lo olvidemos- a «otro procedimiento» análogo. La competencia para fijar esos márgenes concretos -interpretando la normativa comunitaria - y para determinar si la opción adoptada por el legislador nacional está dentro de los mismos corresponde al TJUE. Desde luego, en el momento en el que el TC afirma que «la norma nacional no ha apurado el margen de apreciación que le otorga la europea» está interpretando, obiter dicta, los márgenes que la normativa comunitaria otorga al legislador y admite que, en abstracto, existe dentro de estos, pese a que no diga cuál, una opción legislativa acorde con la doctrina constitucional plasmada en la sentencia.

Cuestión distinta sería concluir que las directivas imponen, sin ningún tipo de margen de apreciación por parte del legislador nacional, el reconocimiento de un derecho unilateral que, según el TC, es inconstitucional por vulnerar el derecho a la tutela judicial efectiva de la entidad aseguradora. Sin embargo, este escenario hipotético desbordaría por completo el propósito de este comentario por cuanto conllevaría necesariamente realizar un análisis serio del Derecho comunitario y los principios que lo integran, su relación con las Constituciones nacionales, su integración como parámetro de enjuiciamiento constitucional y el papel concreto que juegan los tribunales constitucionales de los distintos Estados miembros en su interpretación. 